\title{
The Effect of Construction Related Internships on Academic Studies: Is It Positive or Negative?
}

\author{
Stuart Bernstein \\ Construction Systems \\ University of Nebraska
}

\begin{abstract}
$\underline{\text { Abstract }}$
Is there more pressure to succeed in the field, placed upon the student, by peers and employers, than there is to exceed in the classroom?

This is a pilot study to determine whether or not students' attitudes towards their education change once they have spent time working as interns (for this paper, internships refer to any construction related work experience, including paid, non-paid, part time, and summer positions.) A source of concern is that students are concentrating more on their internships than on their studies, and that they believe the course work is inconsequential to their success. Many construction related programs encourage or mandate internships prior to graduation, and it is proposed to study whether this has any effect on the students' behavior toward their studies as they progress. Another issue is the continuation of the internships into the semester while the student is attempting to handle a full course load. Which becomes more important; work or school? If the student feels, or has been told, they have a position waiting for them upon graduation will they attempt to excel at their course work, or will they settle for merely graduating?
\end{abstract}

It is planned to study the positive and negative effects of internships starting with the Construction Systems students at the University of Nebraska and eventually including students in construction related departments across the country. A survey will elicit responses on their history and opinions of their internships and their academics. The study should eventually include exit interviews with graduating seniors. In addition, alumni should be interviewed to elicit their opinions on the effect of their internships and their education on their careers.

\section{Introduction}

This paper was intended to discover whether student internships have a positive or negative effect on the attitudes of construction students toward their studies. There is an overwhelming agreement among academicians and those in the industry that student internships provide valuable training and experience for the students. This study was designed to find out if there is an attitude among students, who have spent a great deal of time working as interns, that earning top grades is no longer as important as simply graduating, and whether the information being taught to them is 
as important as that being learned on the job.

Due to the small initial data sample, and the format of the survey, a true statistical analysis could not be performed to determine any precise and consequential results. Therefore, this paper will not attempt to correlate information such as semester GPA against number of hours worked during the semester. Instead, this paper will serve as a comparative study to begin the process of investigating the subject and opening channels between this author and other educators to do further research to discover whether there is a correlation between the two as well as other pertinent comparisons. This paper will discuss the results of the survey which show the students' opinions of and attitudes toward their classes and how they relate to their internships.

\section{$\underline{\text { Prior Observations }}$}

The original premise of this paper was based on daily observations made in the classrooms. During one particular class, Personnel and Supervisory Methods, which is taught by this author, some of the students taking this course seemed to have the impression they already knew how to manage people and didn't want to be bothered with the academics of it. In another course, Planning and Scheduling Techniques, some students, who had experience working in the field, insisted there was no need to learn how to allocate or level resources, or how to crunch activities based on cost because "that's not what we do on the job." The attitude, with those particular students, was that these advanced skills were not used by their employers, with whom they intended to continue working after graduation, so what was the purpose of learning it themselves. Admittedly, this negative attitude toward academics is probably held by only a minority of the students, but it is these students who tend to be the most vociferous in the classroom while infecting others with their attitudes of doing as little as possible to succeed.

Through discussions with a number of students who had continued their internships into the semesters while taking a full load of courses, it seemed to become apparent that work took priority over academic studies and assignments. The feeling was, they came to college to get good jobs. They already have good jobs (many of which were guaranteed upon graduation), now they just need to complete the degree requirements to receive the parchment. Any need to excel, earn higher grades, or learn additional information than was absolutely necessary, was overshadowed by the need to work more hours on the job.

\section{$\underline{\text { Data Collection }}$}

This paper was compiled using information garnered from a survey $(n=120)$, developed by this author, and distributed to all of the students (214) in the Construction Systems Department, College of Engineering \& Technology, University of Nebraska-Lincoln, Omaha Campus. Of those distributed, 120 responded. These anonymous surveys were distributed at the end of the fall semester of 2002 (see attached survey.)

Questions 1 through 4, and 13 of the survey were basic demographic questions. Questions 5 through 12 requested information pertaining to GPA, number of hours worked as an intern, and number of credit hours taken during the current semester (reference the attached survey.) Question \#14 was designed to explore the students' attitude toward their classes (see the following.) while questions 15 through 20 were specifically asked to discover how the students felt, either positive or negative, toward their classes after having spent time working in the 
construction field.

\section{Data Results}

\section{Attitude}

The students' opinions, as expressed previously (second paragraph of Prior Observations), along with other comments made to the author, seem contrary to the data collected from the surveys. In setting up a line graph of the results of Question \#14 for each of the different years in school, one would expect to see a positive attitude of the students, toward their classes, to decline from the freshman to senior years. On the contrary, the results show the number of positive attitudes remains high from year to year. This is clearly seen in Figure 1, as the majority of responses to Question \#14 were " $a$ ".

14. Which of the following best describes your attitude toward your classes?(check all that apply)

a. $\square$ Much of what I learn in my classes can be applied to what I do or intend to do.

b. $\square$ I enjoy correlating what the professor is teaching with what I am learning in the field

c. $\square$ Much of what I do in the field can be better understood as a result of what is being taught.

d. $\square$ I feel I know enough about some courses I could teach the class.

e. $\square$ The classes I am taking are not relevant to what I am doing or intend to do.

Table 1. Question \#14 from survey

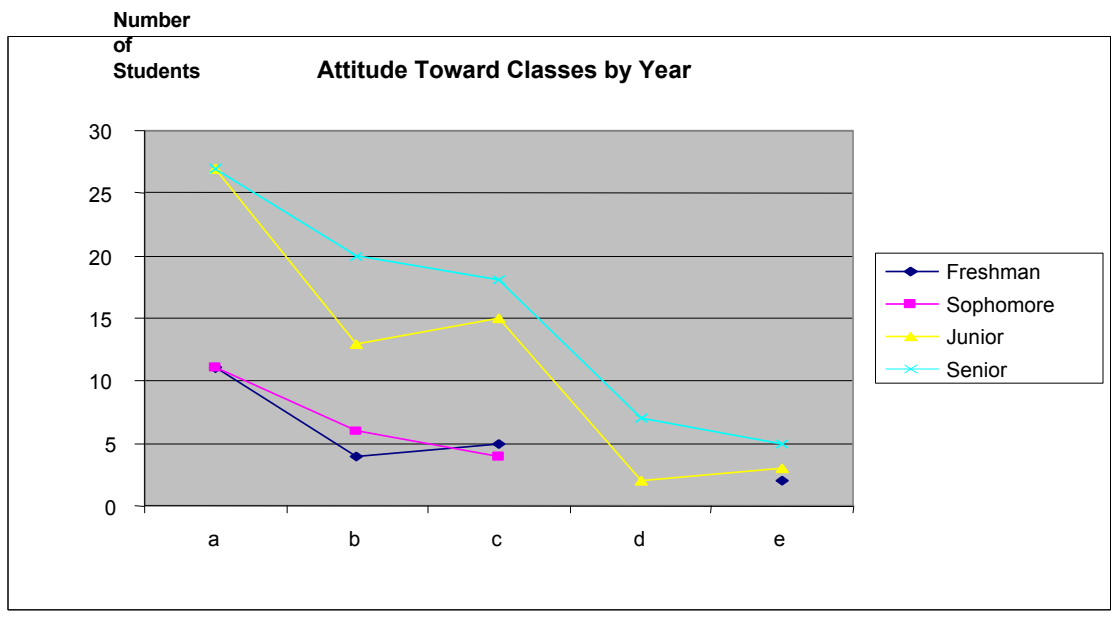

Figure 1. Attitude Toward Classes by Year (Question \#14)

The author realized there were some deficiencies in the way the questions were asked and was not able to compile the data significantly to sufficiently make accurate determinations. It was difficult to determine how to make optimum use of the data received. The best data came from the student responses to questions 15 through 20, which were set up to allow the student to rate the relevance of their coursework, how it related to their internships, and vice versa (see the 
following.)

\section{Perceived Value of Classes and Internships}

Below, you are given the choice of rating an answer from 1 to 5 . Consider 1 as being indicative of the most negative, 3 as being neutral, and 5 as being the most positive.

15. How beneficial to your future career has your internship been?

16. How well do you think your internship will relate to your future classes?

17. How beneficial to, or complementary with, your classes is (are) your internship(s)?

18. How beneficial to, or complementary with, your internship is (are) your classes?

19. How much value do you place on the courses you took which were not directly related to your internship position?

20. How much value do you place on the courses you took which were directly related to your internship position?

\section{Table 2. Questions \#15 through 20 from the survey}

The results from these questions were very interesting and seem to indicate the students who were surveyed felt their course work and their internships were mutually beneficial. This agrees with the report by Williamson and Grankowski, 1996, where they concluded that through internships "a student's perceptions of their practical abilities increases (as) does their personal attitude toward construction course work and professional construction." 4 Figure 2 shows the summation of the results for questions $17-20$. Overall, the results indicate that most of the students remained neutral in their opinions of the benefits and value of their classes in relation to their internships. The results do indicate that the students surveyed leaned in the positive direction on all of the questions as there are a much larger number of students, with an average of $59 \%$, selecting (4) and (5) than there were those selecting (2) and (1), with an average of $8 \%$. In answer to question \#20, which asked for the value of their classes which were directly related to their internships, the results were very positive with forty-one students selecting (5) and another thirty-six students selecting (4). A total of seventy-seven students, approximately two thirds of the total surveyed, responded positively to this question as opposed to only two negative answers.

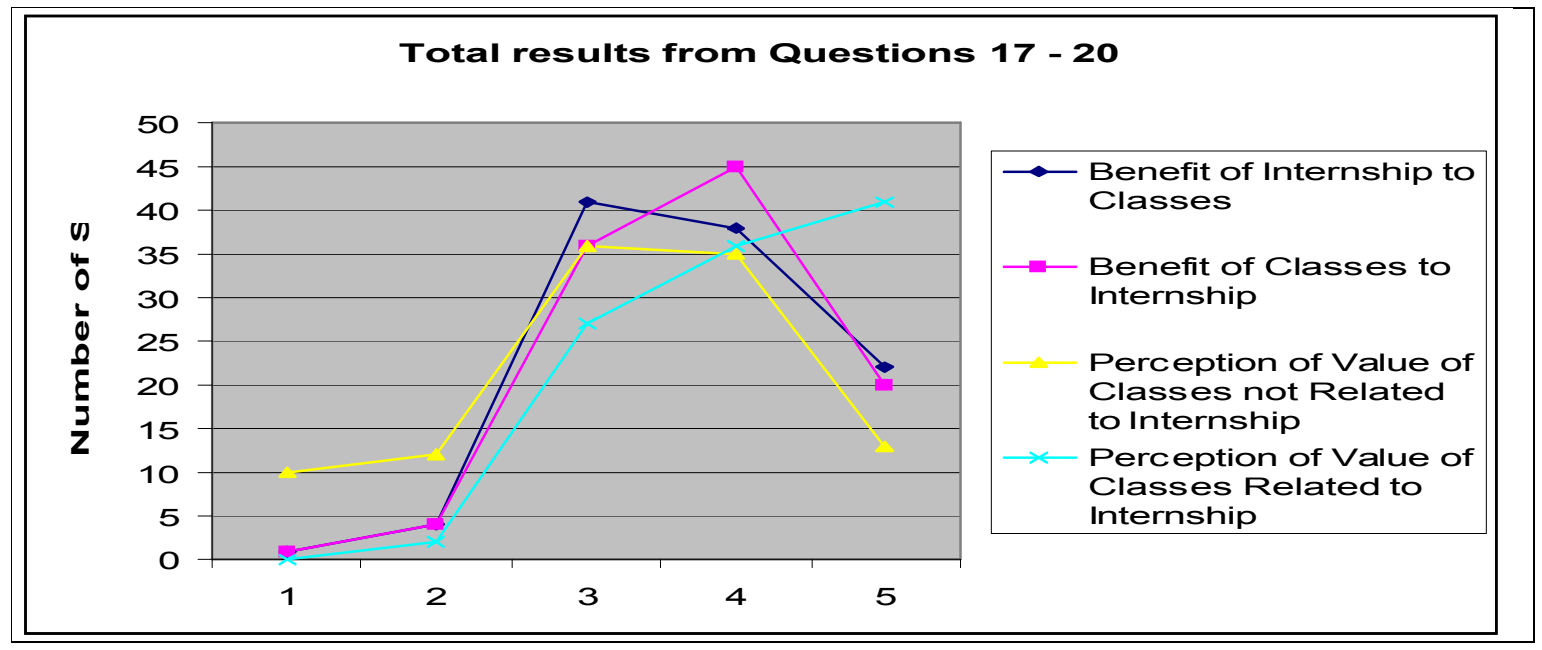

Figure 2. Results from questions 17-20

"Proceedings of the 2003 American Society for Engineering Education Annual Conference \& Exposition Copyright (C2003, American Society for Engineering Education", 
Figure 3 shows the results from questions $17-20$ broken out into individual questions with the data compared by year in school. In each case, the seniors have indicated that they believe their classes and their internships have been mutually beneficial. With the exception of question \#20, the juniors and sophomores were more neutral in their opinion. The freshmen tended to be more positive, except for question \#19 where they remained neutral.
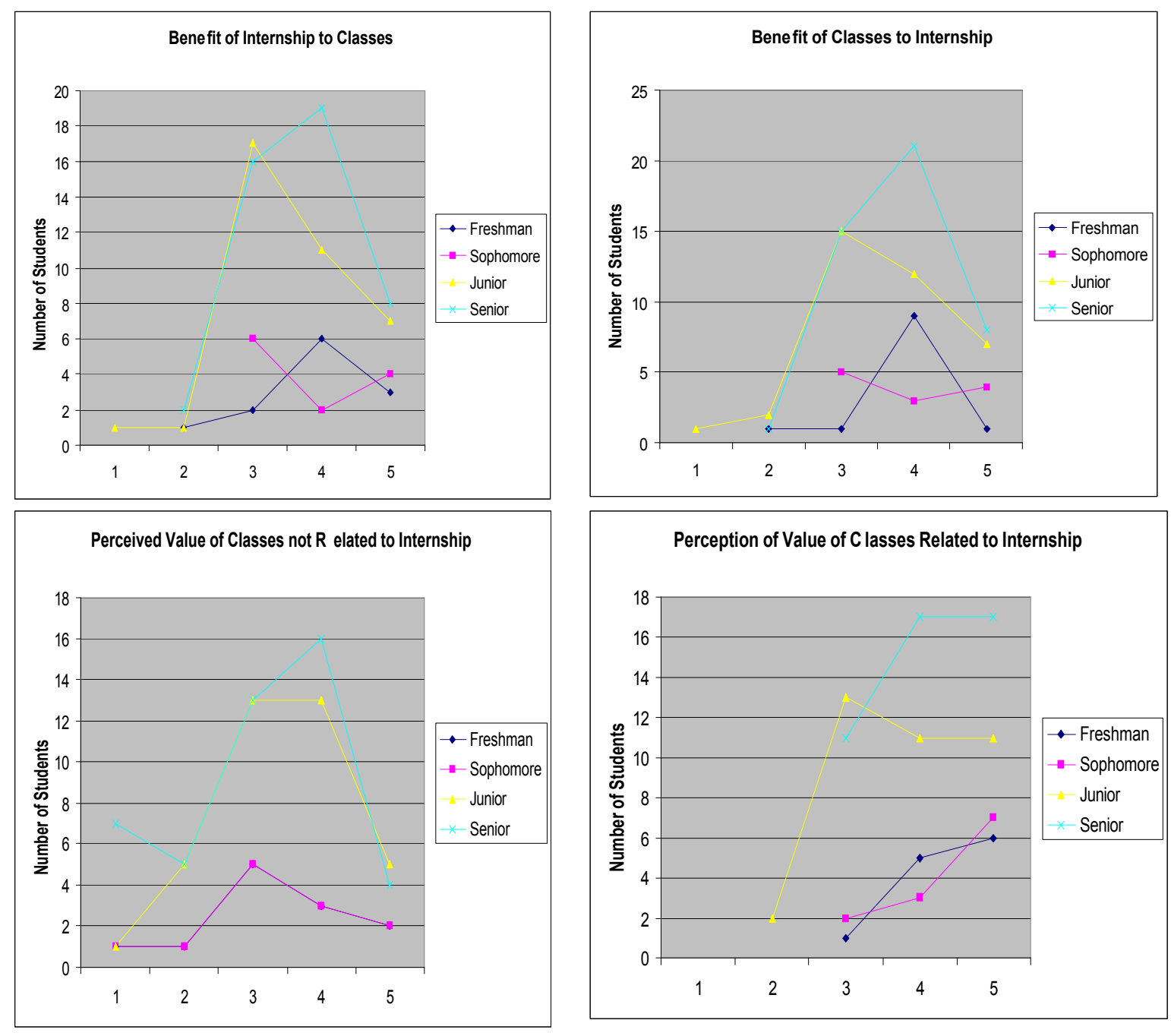

Figure 3. Individual results for questions $17-20$ by year

\section{Credit Hours and Hours Worked During the Fall Semester}

The actual number of respondents was converted into percentages to create the graphs in Figure 4 and Figure 5. Figure 4 indicates that, of the students surveyed, the greatest percentage in all four years worked between 20 and 30 hours per week. The trends were very similar from year to year with the exception of the senior and sophomore students who had approximately $20 \%$ of their members working forty or more hours per week. Only $10 \%$ of the freshmen and juniors surveyed worked that many hours. All four years showed that $10 \%$, or less, of the students worked less than 10 hours per week. 


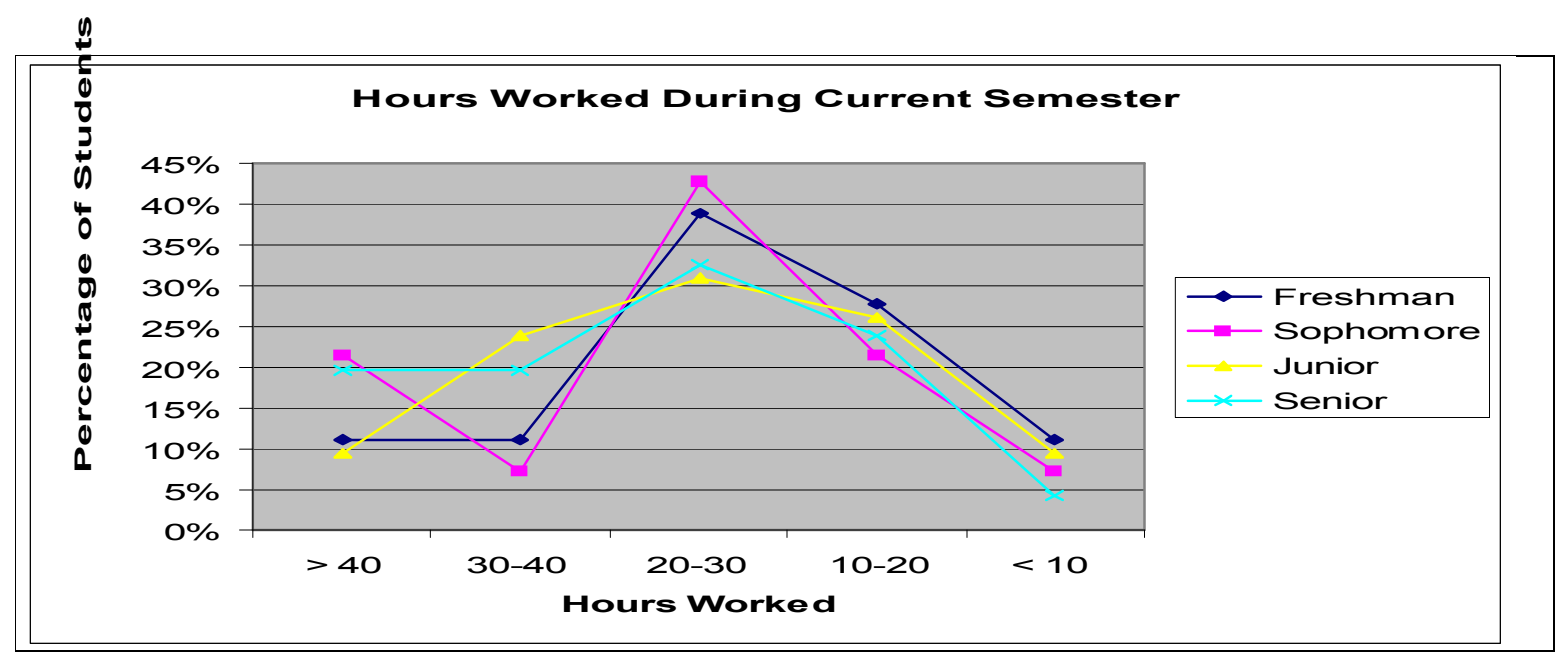

Figure 4. Hours worked during current semester

On the other hand, the number of credit hours taken during the fall semester, by each student, was much more scattered. There were no freshmen or sophomores, and very few juniors, who took 18 or more credit hours. Yet the highest percentage of seniors was in that category. It is the opinion of this author, based on post survey discussions with seniors, that many of them are taking as many credits as necessary to avoid returning to school for another semester. Another surprising factor was that $20 \%$ of the freshmen and sophomores took less than 9 credit hours. This is most likely attributed to the number of hours these students are working outside of school. Not surprisingly, the highest percentage of students overall were in the middle range of both statistics, or 20 to 30 hours of work and 12 to 14 credit hours, which averages 32 to 44 combined hours per week before homework. A follow up study could be done to determine an actual combination of credit hours and hours worked per student as compared to GPA.

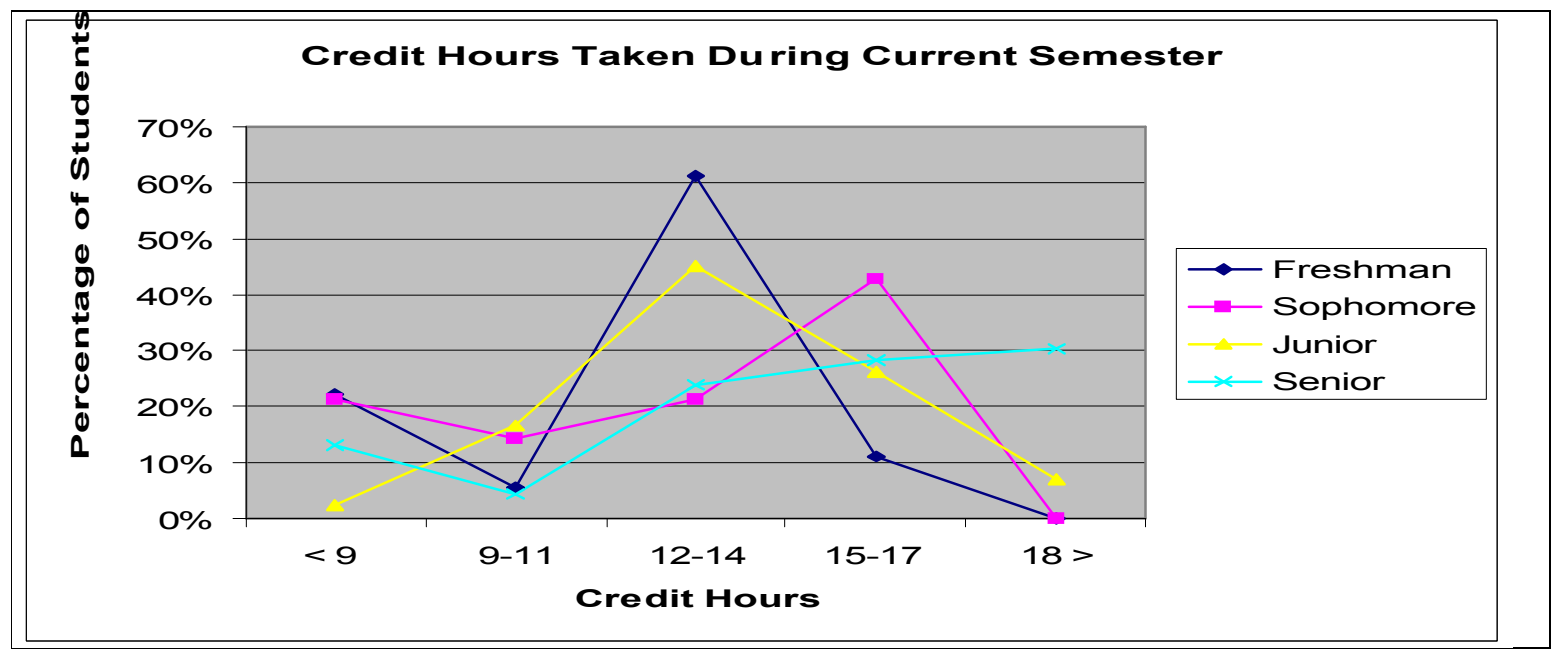

Figure 5. Credit hours taken during current semester

\section{Post Internship Follow-ups}

The University of Wisconsin follows up their student, summer internships with a senior level seminar in which the students report on their work experiences both orally and in writing. This seminar provides an opportunity for the students to discuss their experiences with their peers and 
their professors ${ }^{2}$. It seems this would also be a good opportunity to discuss with the students how their academic courses tie in with their work experiences and open up dialogue on how to better relate course content and field requirements. The seminar could also be used as a forum for employers to discuss what they see as issues with the relationship between the two.

In another study, conducted by an unnamed, Midwestern university, all 66 student respondents supported the idea of requiring internships. The students saw the internships as an excellent way for them to gain employment experience. More than 59\% of the interns agreed that having previous work experience was extremely beneficial in their search for full time employment ${ }^{3}$.

\section{$\underline{\text { Conclusions }}$}

Internships seem to be a critical part of many curricula in universities across the country. It has been stated that the five year retention rate among employees who first serve internships with the same firm is at $100 \%$ versus $30 \%$ for those who don' $t^{1}$. As the deficit in construction workers grows, companies have been looking for every opportunity to hire and retain quality employees. It is no wonder that as an intern proves his worth, companies are quick to encourage the students to continue working with them during the semester. But, as schools make internships a requirement, it is important that we conduct the necessary research to make sure the students are deriving the greatest benefits from their experience and not at the expense of their academic achievements.

At a recent career and internship fair, held by the Department of Construction Systems at UNL, only nine firms participated, and of those nine, only six had positions open for either full or part time employees. Many firms are currently very concerned about the drop in the number of projects available this year. This may have to do with the problems with the economy, the threat of war, or the periodic downturn our industry historically has taken. Whatever the cause, there is genuine concern over the immediate availability of job openings for seniors and interns. If this shortage does manifest, then firms will become less likely to hire just any warm body, and will become more selective in hiring only the best and brightest students. When this happens, students will have to be more concerned with their academics.

The most evident conclusion to be made from this collection of data is that much more work needs to be done in order to do any accurate statistical analysis. Some of the questions in the survey need to be rewritten to make them more conducive to the collection of pertinent data. Also, the method used for compiling the results needs to be further developed so that more and better comparisons can be made.

As mentioned in the abstract, the original intention of this project included exit interviews with graduating seniors and alumni. This was not accomplished at this time and should be looked at as well. Separate questionnaires will need to be written for both the seniors and the alumni.

\section{$\underline{\text { Bibliography }}$}

1. Roe, Andrew, An Evolving Academic Discipline Works to Define its Contribution, Engineering News-

"Proceedings of the 2003 American Society for Engineering Education Annual Conference \& Exposition Copyright $\mathbb{0} 2003$, American Society for Engineering Education” 
Record, October 21, 2002, pp 55-58

2. Fosdick, James A., Post-interns change views of the Media, J-Education, Journalism Educator, July 1979, pp 22-24

3. Hilt, Michael L. and Jeremy H. Lipschultz, Broadcast Newsroom Hiring and Career Preparation, Journalism \& Mass Communication Education, Spring 96, pp 36-43

4. Williamson, Kenneth C. III, Grankowski, Phillip, Measures of Student Empowerment, Attititude, and Motivation Toward Construction Education and the Profession, ASC Proceedings of the $32^{\text {nd }}$ Annual Conference, April 18-20, 1996, pp 149-152

\section{$\underline{\text { Biographical Sketch }}$}

STUART BERNSTEIN is in his first year as an Assistant Professor in the College of Engineering and Technology at the University of Nebraska. After working more than twenty years in the construction industry he returned to school to earn his B.S. in Construction Management at Syracuse University and his M.S. in Architecture from Virginia Tech. Stuart teaches management, scheduling, and estimating in the Construction Systems Department.

\section{Attachments}

Survey developed by this author and used to compile the data in this paper. 


\section{STUDENT INTERNSHIP SURVEY}

Directions: Please fill out the following survey as accurately and honestly as you can. Your thoughtful and constructive input is greatly appreciated. To answer the questions, fill in the $\circ$ next to the answer which best completes the question in your situation.

1 I am currently enrolled in the CET program: No $\quad$ Yes

2. How many years have you been enrolled in the CET program? $\circ 1 \circ 2 \circ 3 \circ 4$

3. My year in college is: Freshman Sophomore Junior Senior

4. My current age is: $18-22 \quad 22-26 \quad 26-30 \quad$ Over 30

5. My overall grade point average is: Below $2.0 \quad 2.5$ to $2.0 \quad 3.0$ to $2.5 \quad 3.5$ to $3.0 \quad 4.0$ to 3.5

6. My expected grade point average for this semester is:
Below 2.0
2.5 to 2.0
3.0 to 2.53 .5 to 3.0
4.0 to 3.5

7. I am enrolled for the following number of credit hours this semester:

Less than 9 hours 9 to $11 \quad 12$ to $14 \quad 15$ to $17 \quad$ More than 18

8. I am currently working the following number of hours per week:

More than $40 \quad 30$ to $40 \quad 20$ to $30 \quad 10$ to 20 s Less than 10

9. How many years of experience in the construction field did you have prior to entering the CET program? oNone $\quad \circ 1 \quad \circ 2 \quad \circ 3 \quad$ oMore than 3

10. Approximately how many total hours have you worked as an intern (for this survey, the term intern and internship refer to a paid construction related job) since entering the CET program?

$\circ 250 \quad \circ 500 \quad 0750 \quad \circ 1000 \quad 01250 \quad 01500 \quad 01750 \quad \circ 2000$

11. Did you work as an intern during the current semester while attending classes? $\quad \circ$ No $\circ$ Yes

12. Which of the following statement(s) best describes your intention?
a. $\bigcirc$ I do not plan on pursuing an internship.
b. $\quad$ I plan on pursuing my first internship this summer.
c. $\quad$ I plan on pursuing another internship with the same company next summer.
d. $\quad$ I plan on pursuing another internship with a different company next summer.
e. $\circ$ I plan on continuing my internship with my current company during the semester.
f. O I plan on continuing my internship with a different company during the semester.

13. Is CET your first curriculum of study or did you transfer over from, or first complete, another program before enrolling in this one?
a. $\circ$ First curriculum
b. $\circ$ Transferred from
c. $\circ$ Completed

14. Which of the following best describes your attitude toward your classes?(check all that apply)
a. $\square$ Much of what I learn in my classes can be applied to what I do or intend to do.
b. $\square$ I enjoy correlating what the professor is teaching with what I am learning in the field
c. $\square$ Much of what I do in the field can be better understood as a result of what is being taught.
d. $\square$ I feel I know enough about some courses I could teach the class.
e. $\square$ The classes I am taking are not relevant to what I am doing or intend to do.

Below, you are given the choice of rating an answer from 1 to 5 . Consider 1 as being indicative of the most negative, 3 as being neutral, and 5 as being the most positive.

15. How beneficial to your future career has your internship been?

16. How well do you think your internship will relate to your future classes?

17. How beneficial to, or complementary with, your classes is (are) your internship(s)?

18. How beneficial to, or complementary with, your internship is (are) your classes?

19. How much value do you place on the courses you took which were not directly related to your internship position? $\begin{array}{llllll}\circ & \circ 2 & \circ 3 & \circ 4 & \circ 5\end{array}$

20. How much value do you place on the courses you took which were directly related to your internship position? 
$\begin{array}{lllll}\circ & \circ 2 & \circ 3 & \circ 4 & \circ 5\end{array}$

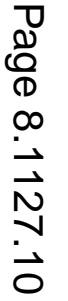

"Proceedings of the 2003 American Society for Engineering Education Annual Conference \& Exposition Copyright (C2003, American Society for Engineering Education" 